\title{
PAHs accumulation in soil-plant system of Phragmites australis Cav. in soil under long-term chemical contamination
}

\section{Svetlana Sushkova ${ }^{\text {a,* }}$, Tatiana Minkina a Sarieh Tarigholizadehb, Elena Antonenko a, Elizaveta Konstantinova a, Coşkun Gülser c, Tamara Dudnikova a, Andrey Barbashev a, Ridvan Kizılkaya c,d}

a Southern Federal University, Rostov-on-Don, Russia

b University of Tabriz, Tabriz, Iran

c Ondokuz Mayıs University, Faculty ofAgriculture, Department of Soil Science and Plant Nutrition, Samsun, Turkey d Agrobigen Research \& Development Trade Ltd.Co, Samsun Technopark, Samsun, Turkey

\section{Article Info}

Received : 19.09 .2019

Accepted : 07.05.2020

\begin{abstract}
Distribution and level of 16 individual and total polycyclic aromatic hydrocarbons ( 2 PAHs) were assessed in soils, roots and above-ground tissues of reed (Phragmites australis) on monitoring plots in the city of Kamensk-Shakhtinskyi (Southern Russia, Rostov Region). The total concentration of the 16 PAHs in soil samples ranged between 499.0 to $7177.9 \mu \mathrm{g} \mathrm{kg}^{-1}$. Samples from the plot no. 4 had the highest PAHs concentrations of $7177.9 \mu \mathrm{g} \mathrm{kg}^{-1}$. The mean concentration of $\sum 16 \mathrm{PAHs}$ in plot no. 3 was noticeably higher than those in other monitoring sites for both root (363.0 $\left.\mu \mathrm{g} \mathrm{kg}^{-1}\right)$ and above-ground tissues $\left(239.8 \mu \mathrm{g} \mathrm{kg}^{-1}\right)$. The distribution of PAHs ring size was in the order of 5-6>4>3>2 in soil samples and HMW PAHs fractions represent $57.3 \%$ of the total PAHs. The concentrations of 3-4 ring PAHs were higher than HMW PAHs with 5-6 aromatic rings in all $P$. australis tissues. Diagnostic ratios of PAHs indicated that anthropogenic activities were probably major sources of PAHs. Accordingly, the maximum accumulation was found for phenanthrene among the 16 priority PAHs in the most of the soil and plants samples. More PAHs were accumulated in roots, as reflected by its higher mean concentration of PAHs in each plot. In addition, the BCF and TF values of LMW PAHs with 2- and 3-rings were higher than those of HMW PAHs. Taken together, our results indicated that there were an intensive accumulation of PAHs in the zone of industrial sewage tanks and sludge reservoirs as well as an obvious translocations of PAHs from the polluted soils to plant tissues, therefore, more attention is required to be paid to the $\mathrm{PAH}$ contamination in this area.
\end{abstract}

Keywords: Plant uptake, polycyclic aromatic hydrocarbons, phragmites australis, soil contamination, translocation.

(C) 2020 Federation of Eurasian Soil Science Societies. All rights reserved

\section{Introduction}

Polycyclic aromatic hydrocarbons (PAHs) are considered as one of the most significant organic pollutants existing in environment as complex mixtures of many components. These compounds are ubiquitous and persistent in the nature and consist in two or more condensed benzene rings which arrange in linear,

\begin{tabular}{l} 
* Svetlana Sushkova \\
Tatiana Minkina \\
Sarieh Tarigolizadeh \\
Elena Antonenko \\
Elizaveta Konstantinova \\
Coşkun Gülser \\
Tamara Dudnikova \\
Andrey Barbashev \\
Rıdvan Kızlkaya \\
\hline
\end{tabular}

:

terra_rossa@mail.ru tminkina@mail.ru s.tarigholizade@yahoo.com antonenko1102@yandex.ru konstantliza@gmail.com cgulser@omu.edu.tr tyto98@yandex.ru barbashev_andrei@mail.ru ridvank@omu.edu.tr
0000-0003-3470-9627 0000-0003-3022-0883 0000-0003-0609-3730 0000-0002-8603-4038 0000-0002-9836-8721 0000-0002-6332-4876 0000-0002-8436-0198 0000-0003-1857-948X 0000-0001-7475-9851 
angular, or cluster structures (Haritash and Kaushik, 2009; Li et al., 2014). PAHs are capable of accumulation in plants (as a main food source for human and animals) and subsequently they can easily enter into food chain, therefore, affect living organisms owing to their toxic, mutagenic, teratogenic, and carcinogenic properties (Keith and Telliard, 1979; Čvančarová et al., 2013). In general, PAHs are originated from a broad range of natural and especially anthropogenic sources, such as traffic and industrial activity, through the combustion of oil, wood, and other organic materials (Gworek et al., 2014; Serafimovski et al., 2014; Krzebietke et al., 2018).

The contamination of soil, sediment, and groundwater can led to subsequent plant contamination (Chang et al., 2013). Plants have also the capacity of uptake and accumulation of PAHs from polluted areas playing a vital role in their remediation. The accumulation of PAHs in plants as a primary component of terrestrial ecosystems will cause the subsequent transfer of these pollutants into the higher trophic levels (Aina et al., 2006; Zuo et al., 2006). Considering this regard, it is important to distinguish the ways of these pollutants' absorption by plants. PAHs, similar with other organic pollutants, are taken up by plants through two major routes (either from soil or air) (Chang et al., 2013;_Gworek et al., 2016). However, there are other pathways for PAHs entering into plant tissues including shoot uptake via root (Burken and Schnoor, 1997), shoot uptake via soil or air ( $\mathrm{Li}$ and Chen, 2014). There is increasing evidence showing that roots are one of the main routs responsible for the absorption and accumulation of most of the detected PAHs in the soil-plant system as being first tissues that comes in contact with pollutants (Zhang et al., 2017a,b). Subsequently, they translocate from root to shoot through transpiration stream flux (Dettenmaier et al., 2009; Chen et al., 2015). Some studies carried out by fluorescence microscopy have illustrated the uptake and translocation mechanism in roots of maize Zea mays (Dupuy et al., 2016) and in the roots and shoots of Medicago sativa (Alves et al., 2017). In general, the absorption of organic contaminants by roots can occur via passive diffusive partitioning (i.e. apoplastic) and/or active (i.e. symplastic) transport which the latter is mediated by H+-coupled symporters (Zhan et al., 2018). However, to date, little information is available about the mechanisms involved in these movements (Dupuy et al., 2016; Zhan et al., 2018). PAHs uptake, distribution as well as their toxic impacts on plants depend on initial concentrations and chemical properties of PAHs, physico-chemical properties of soil, and plant species (Zhang et al., 2017a,b) and the movements of PAHs through soil-plant system mostly occur due to their low solubility and high octanol-water partition coefficient. It appears that most of the PAHs with $\log$ Kow $<4$ are more likely accumulate via roots, then translocate to other plant tissues, whilst high hydrophobic PAHs with log Kow $>4$ may strongly adsorb on the root epidermis and are unlikely to be penetrate into the inner roots and translocated within the plant (Zhang et al., 2017a,b).

Previous studies suggested that some plants have the capacity to efficaciously uptake and accumulate PAHs (Gałuszka, 2007; De Nicola et al., 2008; Klánová et al., 2009). It seems that the impact of PAHs on wetland plants is species-specific regardless of PAH types and media (Zhang et al., 2010). However, Phragmites australis Cav. can serve effectively as PAHs bioaccumulator for the removal of different organic and inorganic contaminants (Davies et al., 2005; Bonanno, 2011, 2013). The accelerated removal of pyrene and benzo(a)pyrene by the root exudates of $P$. australis was previously reported by Toyama et al. (2011). They also suggested that phenolic compounds in root exudate of $P$. australis can support the Mycobacterium spp. growth resulting in stimulation of biodegradation of pyrene and benzo(a)pyrene in the $P$. australis rhizosphere sediment. It seems that $P$. australis accelerated the oxidation of the PAHs by rhizodegradation. Also, in some other studies this species was introduced as an efficient aquatic plants for the depletion of an aged PAHs contamination as well as tolerating high levels of organic contaminants (Di Gregorio et al., 2014; Alwan, 2016). Furthermore, the capability of P. australis in accumulation of PAHs were examined by Cui et al. which found that P. Australis accumulated PAHs effectively compared to native plants with higher accumulation of MMW and HMW PAHs in leaves than in roots and stems (Cui et al., 2015).

The objective of current study was the assessment of plant efficiency in PAHs accumulation and to determine biological concentration factor (BCF) and translocation factor (TR) of PAHs in Phragmites australis plants grown in soils located in the Seversky Donets River floodplain, southern Russia, Rostov Region. Furthermore, a compositional profile of LMW and HMW PAHs compounds in soil, root and aboveground parts of this species were investigated, as well.

\section{Material and Methods}

\section{Object of study}

The research soils were located in the Seversky Donets River floodplain, southern Russia, Rostov Region. The studied soils situated on the territory of the Lake Atamanskoe former used as a wastewater disposal basin for the chemical factory after 1950s and was a dried up oxbow in 1990s (Figure 1.). The plants under 
the study were represented by mesophilic succession of the Lake Atamanskoe by common reed (Phragmites australis Cav.), which adapts due to its remarkable ecological resilience (Jiang and Wang, 2008). Other dominant plants of floodplain lakes were reed mace (Typha spp.), bulrush (Scirpus lacustris), water plantain (Alisma plantago-aquatica), rush flower (Butomus umbellatus), sedges (Carex spp.), etc. These plants are not tolerate to high water mineralization, high level toxic metal salts, or organic pollutants (Privalenko et al., 2000).
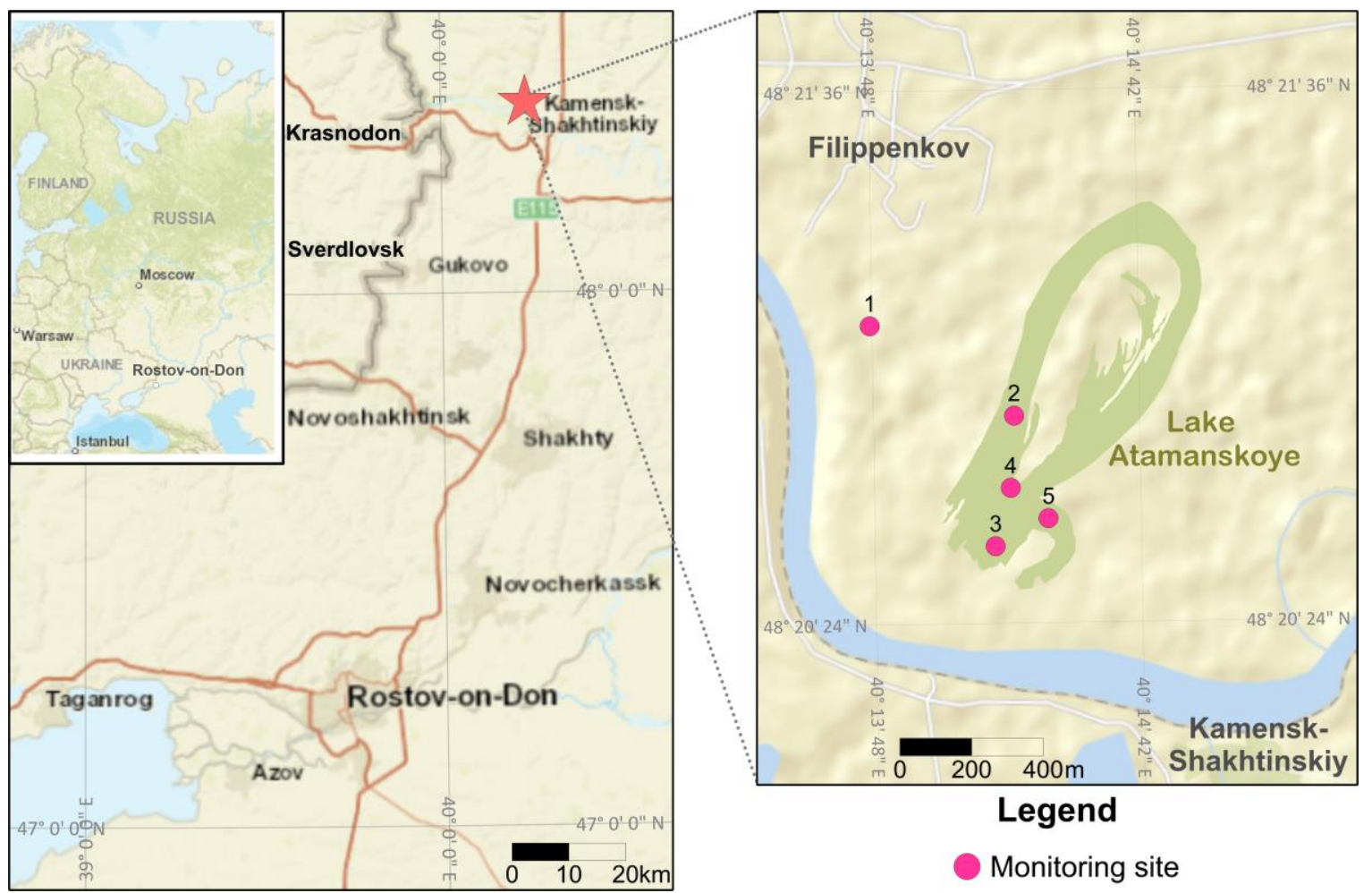

Figure 1. General schematic of the region under study. Monitoring plots are denoted with circles

\section{Monitoring plots}

The 100 soil monitoring plots grid was established in 2015-2017 for the object study. The sampling depth was 0 to $20 \mathrm{~cm}$ and soils were selected according ISO 10381-1 (2002). Four monitoring plots with high levels of anthropogenic pollution adjacent to the lake were selected. The soil on monitoring plot no. 1 was taken as a background, because it was located at $2 \mathrm{~km}$ from the pollution source and represents an analogue of the initial soil (Figure 1), which was classified as a Fluvisol (according to IUSS, 2015). The anthropogenically transformed soils on plots no. 2-5 are classified as Spolic Technosols.

\section{Chemical analysis}

\section{Soil}

In each area, four soil samples were collected from the surface (0- to 20-cm) horizons. They were stored in polyethylene bags and taken to the laboratory. The soil samples from the same area were mixed, air-dried, sieved through a $2 \mathrm{~mm}$-sieve, and homogenized. The main physical and chemical characteristics of the soil were determined at the certified analytical laboratory (Certificate No. POCC RU 0001.511127) in following ISO Guide 34 (2009) methods. The particle size distribution was determined by the pipette method (with pyrophosphate procedure preparation) (Shein, 2009). In this method carbonates, organic matter, $\mathrm{Fe}$, and $\mathrm{Al}$ oxides were not removed before the pipette procedure. The $\mathrm{pH}$ in $\mathrm{H}_{2} \mathrm{O}$ suspension was determined using a glass electrode in a 1:5 (volume fraction) suspension of sample in water according to ISO 10390 (2005), organic carbon content by sulfochromic oxidation, ISO 14235 (1998), carbonates content by using a Scheibler apparatus, ISO 10693 (1995), and exchangeable cations using a hexamminecobalt trichloride solution, ISO 23470 (2011).

\section{Plants}

Common reed (Phragmites australis Cav.) is a cenosis-forming species on the established monitoring plots. Standard cuts for the morphobiometric measurements of reed plants on the monitoring plots were performed in the second half of August, when the vegetative and generative organs of reed plants reach maximum. On each monitoring plot, an average sample was formed from 8-10 individual samples containing plants of the same species. Soil was removed from roots and rhizomes. 


\section{PAHs extraction and determination}

PAHs were extracted from the soils and plants of the objects under study by the standard method using for the removal of the interfering soil components by saponification (Directive document 52.10.556-95, 2002; Sushkova et al., 2015; 2016).

A 1-g portion of the prepared soil was put in a pear-shaped flask for rotary evaporator; $20 \mathrm{~mL}$ of $2 \% \mathrm{KOH}$ solution in ethanol was added, and the mixture was refluxed on a water bath for $3 \mathrm{~h}$. The saponification of lipids and gummy soil components occurred during the refluxing, which increased the recovery of PAHs and reduced the amount of coextracted substances in the extract. The supernatant was decanted into an Erlenmeyer flask, and $15 \mathrm{~mL}$ of $\mathrm{n}$-hexane and $5 \mathrm{~mL}$ of distilled water were added for the better separation of the layers. The mixture was shaken on a rotary shaker for $10 \mathrm{~min}$ and transferred into a dividing funnel. The hexane layer was poured into a separate vessel. The residue in the flask was extracted twice more in a similar way. The combined hexane extract was washed with distilled water to neutral $\mathrm{pH}$ (using litmus as an indicator), transferred into a dark vessel with a close lid, and desiccated by adding $5 \mathrm{~g}$ of anhydrous $\mathrm{Na}_{2} \mathrm{SO}_{4}$. After exposure at $+5^{\circ} \mathrm{C}$ for $8 \mathrm{~h}$, the desiccated extract was decanted into a dry round-bottomed flask and evaporated to dry on a rotary evaporator at a bath temperature of $40^{\circ} \mathrm{C}$. The dry residue was dissolved in 1 $\mathrm{mL}$ of acetonitrile.

The content of PAH in the test samples was determined by the external standard method (Procedure of measurements..., 2008). The content of PAH in the soil was calculated from the equation

$$
\mathrm{C}_{\mathrm{s}}=\mathrm{k} \mathrm{S}_{\mathrm{i}} \times \mathrm{C}_{\mathrm{st}} \times \mathrm{V} /\left(\mathrm{S}_{\mathrm{st}} \times \mathrm{m}\right)
$$

where $C_{s}$ is the content of PAH in the soil sample $(\mu \mathrm{g} / \mathrm{kg}) ; \mathrm{S}_{\mathrm{st}}$ and $\mathrm{S}_{\mathrm{i}}$ are the BaP peak areas for the standard solution and the sample, respectively; Cst is the concentration of the standard PAH solution $\left(\mu \mathrm{kg}^{-1}\right)$; $\mathrm{k}$ is the recovery factor of PAH from the sample; $\mathrm{V}$ is the volume of the acetonitrile extract $(\mathrm{mL})$; and $\mathrm{m}$ is the mass of the sample (g). The efficiency of target PAHs extraction from soils was calculated using a spike matrix (Yaroshchuk et al., 2003; Sushkova et al., 2017).

Samples were analyzed for PAHs with an Agilent 1260 Infinity high performance liquid chromatograph (HPLC) equipped with a fluorescence detector following the ISO 13859:2014 requirements. The HPLC system was fitted with reversed phase column Hypersil BDS C18 $(125 \times 4.6 \mathrm{~mm}, 5 \mu \mathrm{m})$ and a mixture of acetonitrile and ultrapure water as the mobile phase. Sixteen priority PAHs were measured in the present study: naphthalene (NAP), biphenyl (BIP), anthracene (ANT), acenaphthene (ACE), acenaphthylene(ACY), fluorene (FLU), phenanthrene (PHE), benzo[a]anthracene (BaA), pyrene (PYR), fluoranthene (FLT), chrysene (CHR), benzo[a]pyrene $(\mathrm{BaP})$, benzo[b]fluoranthene $(\mathrm{BbF})$, benzo[k]fluoranthene $(\mathrm{BkF})$, benzo[ghi]perylene (BghiP), dibenzo[a,h]anthracene (DBA). Compounds were identified by comparing the retention times to that of the analytical standard samples.

Quality control of every HPLC detection was performed according Agilent Application Solution (ISO 138772005). Individual standard solutions were purchased from the Sigma-Aldrich (Merch). A calibration standard of PAH mixture was injected after every six samples to correct for drift in retention time within a run. The certified reference materials and calibration curves were used for calculation of the limits of detection (LODs) and limits of quantification (LOQs) have been presented previously (Minkina et al., 2019). For the developed methods of extracting the target PAH in the soil, a random component of the measurement error was estimated, which for the concentration range of $2-200 \mu \mathrm{g} \mathrm{kg}^{-1}$ was $3.5-14 \%$.

Data are expressed as a root concentration factor (RCF) where RCF) root concentration (mg g-1)/solution concentration ( $\mathrm{mg} \mathrm{mL}^{-1}$ ), shoot concentration factor (SCF) where SCF) shoot concentration (mg g-1)/solution concentration (mg mL $\left.\mathrm{m}^{-1}\right)$ and as a transfer factor (TF) where TF) shoot concentration (mg g-1)/root concentration ( $\mathrm{mg} \mathrm{g}^{-1}$ ).

\section{Calculation of BCF and TF}

PAHs uptake from soil to roots and ground-parts was calculated using following equations according to Bech et al. (2014):

$$
\begin{gathered}
\mathrm{BCF}=\mathrm{C}_{\text {root }} / \mathrm{C}_{\text {soil }} \\
\mathrm{TF}=\mathrm{C}_{\text {above-ground parts }} / \mathrm{C}_{\text {root }}
\end{gathered}
$$

Where TF is BCF is the Biological Concentration Factor and Translocation Factor, respectively.

\section{Statistical analysis}

All data were processed using Microsoft Excel 2018 software and statistically analyzed using SPSS-22 software. The data presented as mean \pm standard division (S.D.) of three independent replications using oneway ANOVA. Statistically comparison among the means was carried out by Tukey's range tests and differences were considered significant at $\mathrm{p} \leq 0.05$. 


\section{Results}

\section{PAHs content and distribution}

The determination of PAHs content in the $20 \mathrm{~cm}$ soil layer of monitoring plots showed an intensive accumulation of PAHs. The total concentration and composition of 16 priority PAHs according to their ring numbers in the $20 \mathrm{~cm}$ soil layer of monitoring sites and, also in plants grown in contaminated sites were shown in Figure 2. The data on the content of $\sum_{16}$ PAHs in $20 \mathrm{~cm}$ layer in soil of monitoring site no. 1 was $499.0 \mu \mathrm{g} \mathrm{kg}^{-1}$. The total concentration of $\sum_{16} \mathrm{PAH}$ in soil of site no. 2, 3, 4, and 5 were 5073.2, 1941.1, 7177.9, and $1465.8 \mu \mathrm{g} \mathrm{kg}^{-1}$, respectively (Figure $2 \mathrm{~A}$ ). The most affected monitoring site was no. 4 with maximum of 16 priority PAHs total concentration (7177.9 $\mathrm{g} \mathrm{kg}^{-1}$ ) in soil (Figure 2A). As it is shown in figure 2A, the comparison data analysis for the dominant PAHs type in $20 \mathrm{~cm}$ soil layer of plot no. 1 (located far from the dry lake) and all soil samples from the monitoring plots situated within the former lake area showed significant differences. The mean concentration of two- and three-ring PAHs in soil samples were in the range of 14.6 to $511.4 \mu \mathrm{g} \mathrm{kg}^{-1}$ and 120.7 to $1423.1 \mu \mathrm{g} \mathrm{kg}^{-1}$, respectively. Two rings PAHs was in their lowest amounts followed by three rings in all plots. By contrast, the concentration of five-six ring PAHs was significantly high in soil samples except for plots no. 1 and 5 which replaced by four rings (Figure 2A).

A

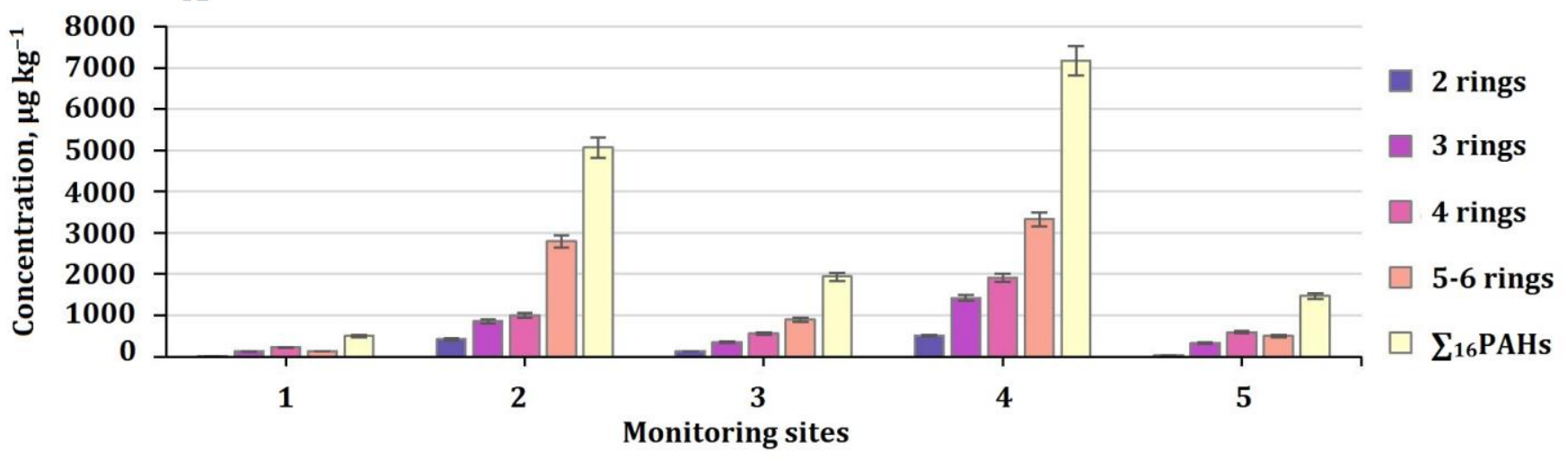

B

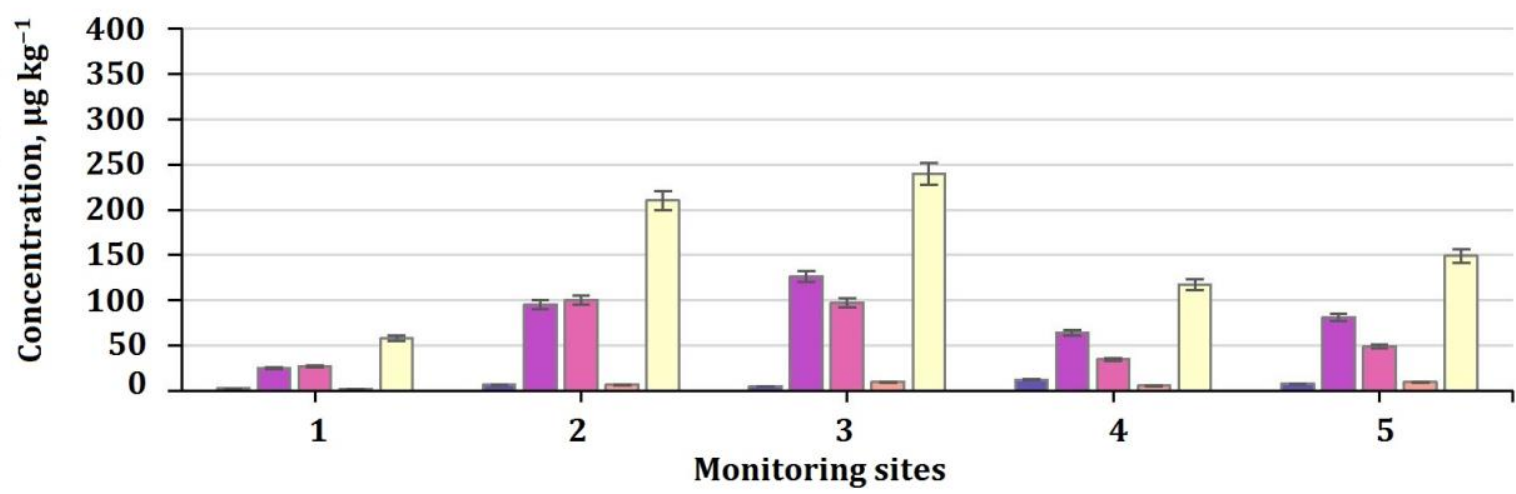

2 rings

3 rings

4 rings

5-6 rings

¿16 PAHs

C

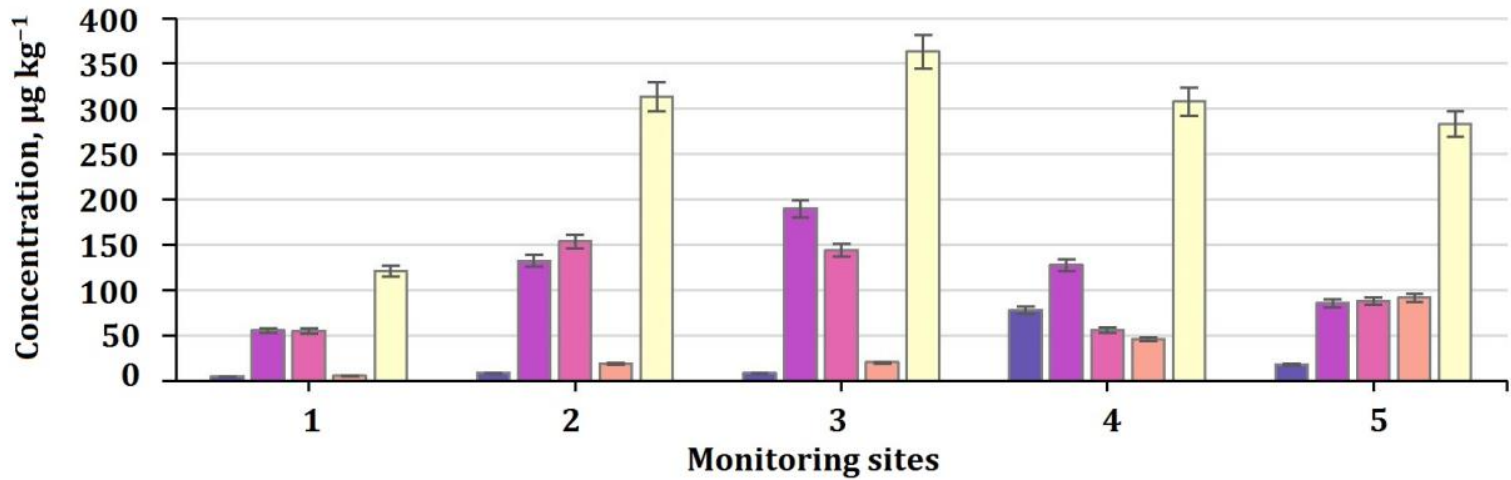

2 rings

3 rings

4 rings

5-6 rings

$\sum_{16}$ PAHs

Figure 2. The concentration of $\sum 16$ PAHs in the $20 \mathrm{~cm}$ soil layer of monitoring sites and in P. australis grown in contaminated sites. The hanging bars is the average means standard division between three replications. 
As it is shown in Figures 3A, the comparison data analysis for the dominant PAHs type in $20 \mathrm{~cm}$ soil layer of plot no. 1 (located far from the dry lake) and all soil samples from the monitoring plots located within the former lake area showed significant differences. It was found that the content of high molecular weight (HMW) PAHs such as DBA (no. 2), BbF (no. 4) and BghiP (no. 2, 3 and 5) prevailed to low molecular weight (LMW) PAHs. However, in all area, PHE, CHR=BbF, BghiP, and DBA were the major PAH compounds, accounting for $13.4 \%, 12.2 \%, 11.5 \%$, and $9.2 \%$ of the total PAHs, respectively, followed by FLT=PYR (8.4\%). The contribution of ACY, ACE, FLU, and BIP was low, and they accounted for $<2 \%$ of the total PAHs. LMW (2 and 3 rings) and MMW-HMW (4 and 5-6 rings) PAHs accounted for 25.9\% and $74.1 \%$ (57.3\% for HMWs only) of the total PAHs, respectively (Figure 3A).
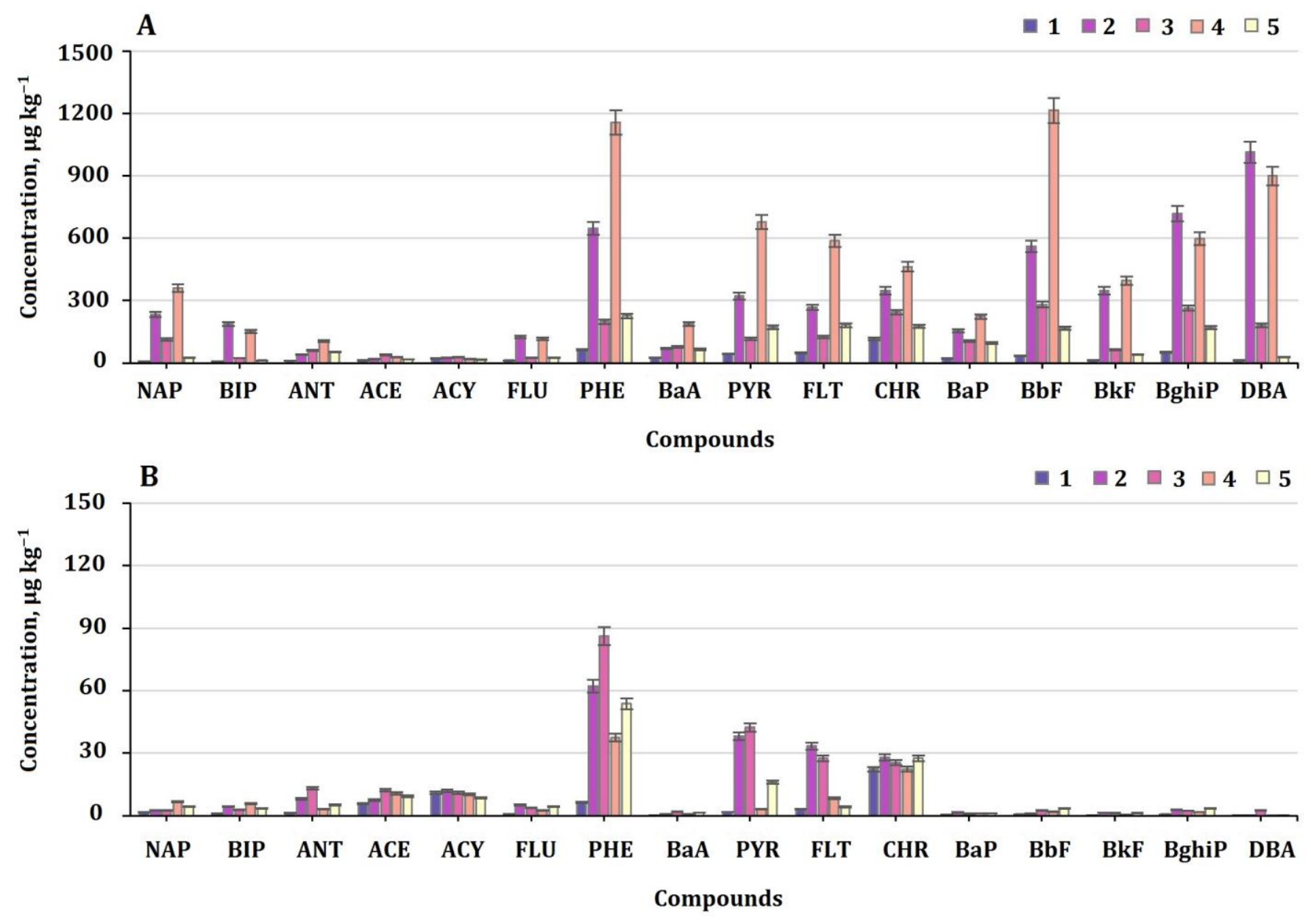

C

$\square 1 \square 2 \square 3 \square 4 \square 5$

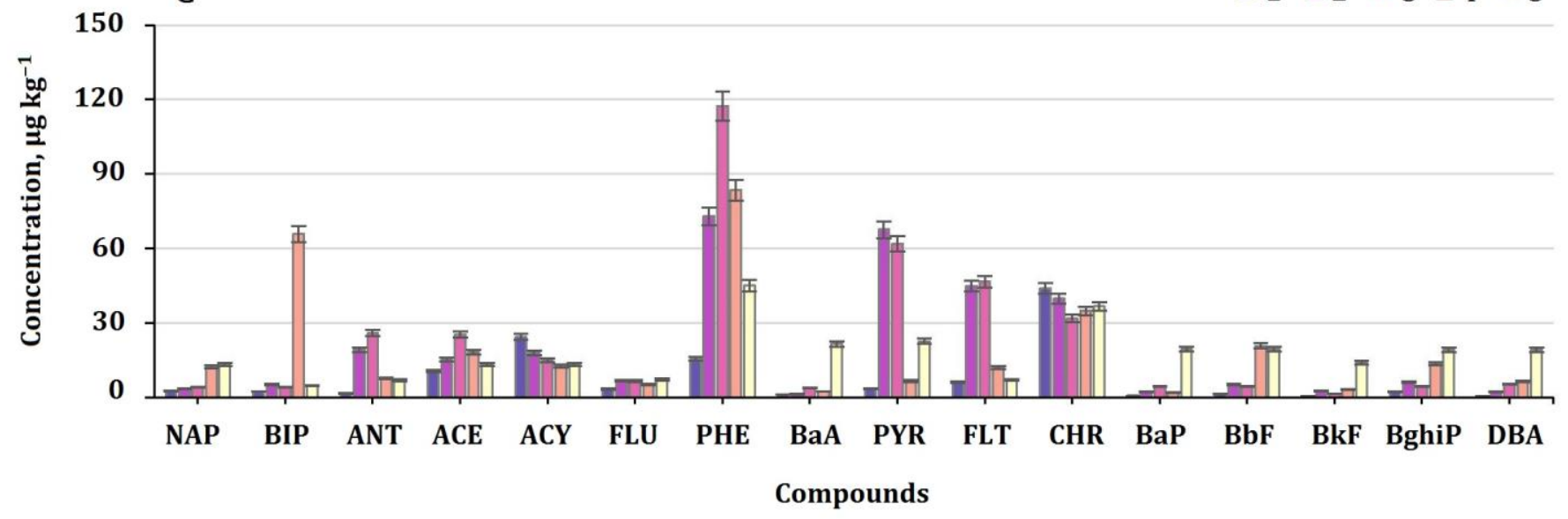

Figure 3. Individual PAHs concentrations in $20 \mathrm{~cm}$ soil layer of monitoring plots (A), Phragmites australis Cav. roots (B) and above-ground parts (C), $\mu \mathrm{g} \mathrm{kg}{ }^{-1}$. The hanging bars is the average means standard division between three replications. 
After determining the content of PAHs in soils, the content of PAHs in the P. australis plants growing in them was also analyzed. The total concentration of 16 priority PAHs in plants grown in contaminated sites is shown in Figures 2B and C. The total concentration of 16 priority PAHs in the above-ground parts of $P$. australis plants for site no. 2, 3, 4, and 5 were 210.2, 239.8, 117.6, and $149.0 \mu \mathrm{g} \mathrm{kg}^{-1}$, respectively (Figure 2B). The content of 16 PAHs in roots of $P$. australis also varied among contaminated plots and were 313.5, 363.0, 308.0, and $283.1 \mu \mathrm{g} \mathrm{kg}^{-1}$ for plots no. 2, 3, 4, and 5, respectively (Figure 2C). In both root and above-ground parts, plot no. 1 was the least polluted and samples taken from this plot had the lowest content of total PAHs in both roots (120.9 $\left.\mathrm{g} \mathrm{kg} \mathrm{k}^{-1}\right)$ and above-ground parts (58.1 $\left.\mu \mathrm{g} \mathrm{kg}^{-1}\right)$ of P. australis (Fig. $2 \mathrm{~B}$ and C). Plants growing in site no. 3 prevailed with total PAHs concentration of 363.0 and $239.8 \mu \mathrm{g} \mathrm{kg}^{-1}$ for roots and aboveground parts, respectively (Figure $2 \mathrm{~B}$ and $\mathrm{C}$ ).

The dominant PAHs content was found to be mostly LMW and MMW PAHs in P. australis plants, including PHE (no. 2-5) and CHR (no. 1) (Figure 3B and C). The composition and dominant PAHs in P. australis plants were similar and the mean concentrations of PHE and CHR in different sample materials on the control monitoring plot (no. 1) and other plots were $22.3 \%$ and $16.4 \%$ in roots, and $28.9 \%$ and $20 \%$ in above-ground parts, respectively. PYR was the third most abundant PAH with respective percentage concentration of $10.3 \%$ and $10.5 \%$ in roots and above-ground parts, followed by FLU and ACY. The least amount of PAHs was for 5-6 rings and 2 ring PAHs. On the other words, BkF, BbF, DBA, BaP, NAP, and BIP occurred in lowest amounts in the plants collected from monitoring sites (Figure $3 \mathrm{~B}$ and $\mathrm{C}$ ).

\section{Bioconcentration Factor (BCF) and Translocation Factor (TF)}

The BCF of $\sum_{16} \mathrm{PAHs}$ in monitoring plots were presented in Figure 4. The mean BCF of LMW PAHs with 2- and 3-rings (0.4) was 3.6 times higher than that of HMW PAHs (0.11) (except for DBA as a HMW PAHs which showed higher BCF only in plot no. 5), as LMW PAHs were easier to be absorbed by $P$. australis plants than the HMW ones. The greatest BCF value was for ACY (21\%) followed by ACE (20\%) and BIP (8\%) (Figure 4). Root to above-ground part transfer factors (TFs), defined as the ratio of the contents of PAHs in the aboveground part to the roots, were also calculated (Figure 4). Although there was no big difference between TF values for LMW and HMW PAHs (all values were less than 1), TF recorded the highest values for the 2-4 ring PAHs in monitoring sites (Figure 4) and generally decreased by increment in KOW of PAHs. TF values from the highest to the lowest ones were as: PHE > FLT=ACY=CHR followed by mostly LMW and MMW PAHs including ACE, ANT, BIP, NAP, FLU, and PYR with almost the same TF values $(p<0.05)$ (Figure 4).
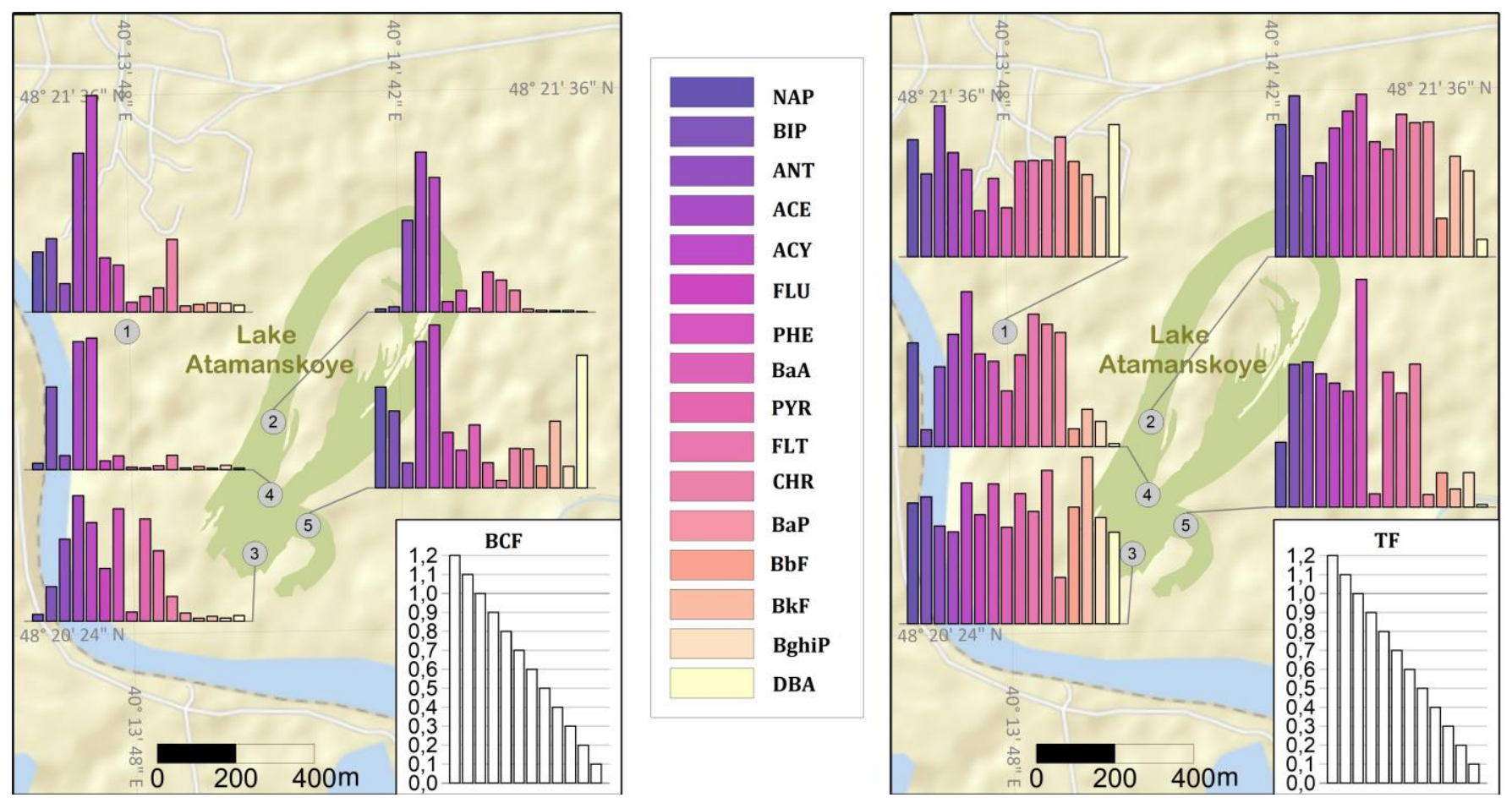

Figure 4. The Bioconcentration factor (BCF) and translocation factor (TF) of 16 priority PAHs compounds in P. australis.

\section{Discussion}

PAHs do not present as a separate entity in the environmental media and mostly their mixture concentration is considered for explaining their distribution. Here, the distribution pattern of the 16 priority PAHs 
recommended by the United State Environmental Protection Agencies (US EPA) were investigated. According to the number of aromatic rings, the 16 PAHs were divided into four groups: 2-ring, 3-ring, 4-ring, and 56ring PAHs and the sequence of proportion in all surface soils were 5.6\%, 20.4\%, 32.4\%, and 41.6\%, respectively. The obtained results illustrated that the soil samples in each plot had different content and compositions of PAHs. As mentioned above, the most affected monitoring site was no. 4 with maximum of $\sum_{16} \mathrm{PAHs}$ concentration in soil, however, plants growing in site no. 3 prevailed with total PAHs concentration in both root and above-ground parts (Figure 2). It seems that plants grown in highly contaminated plot (no. 4) probably prevent the uptake of PAHs in order to manage the contamination. In the reports by Gworek et al., it has been suggested that the difference in the PAH content in different plots is likely associated with the significant difference in organic matter content of soils (Gworek et al., 2016). Based on the data, 5-6 ring PAHs were registered in soils of studied territory as the most abundant (Fig. 2A). Therein, BbF, BghiP, and DBA were found to be the most prominent compounds in all soil samples except for CHR and PHE in soils no. 1 and 4, respectively. The predominance of HMW PAHs in monitoring plots (57.3\%) suggests that the sources of PAHs might be caused by high level of anthropogenically contributed PAHs such as emission from industrial activity and heavy traffic in these areas (Jiao et al., 2017). In accordance with this regard, another report also demonstrated that high-temperature combustion process including incomplete fuel combustion and vehicle engine emissions are the main source for HMW PAHs, while LMW PAHs were mainly generated by low-or moderate-temperature combustion processes (such as biomass combustion and domestic coal burning) (Sun et al., 2010).

PAHs uptake and distribution can differ remarkably depending on many factors including plant species, initial soil concentrations of PAHs and microbial population (Ryan et al., 1988). Due to direct connection, roots are usually the major reservoir for pollutants and despite strong adsorption to soil particles, high hydrophobicity, and low bioavailability of PAHs, some of them are taken up by plants (Wang et al., 2015). Plants can accumulate PAHs from a polluted area through two main pathways: (1) root uptake from contaminated soils: (2) deposition on the waxy leaf cuticle or through stomata. PAHs can subsequently transfer to above-ground parts of plants (Li et al., 2016; Zhang et al., 2017a,b). The amount of total PAHs in soils is generally higher than in plants (Wang et al., 2012) which is in accordance with present study.

All the 16 PAHs were detected in P. australis tissues, however, the dominant PAHs in roots and above-ground parts of $P$. australis possessed mostly three rings (PHE) and four rings (CHR). This may be attributed to their higher solubility and volatility due to their molecular size and lower persistence in the environment which in turn result in their easy biodegradation or translocation when compared to HMWs (Zohair et al., 2006; Gworek et al., 2016). Similarly, higher LMW PAHs accumulation in vegetable with the contribution of $60 \%$ and $45.8 \%$ of $\Sigma_{16} \mathrm{PAH}$ in Pakistan and China, respectively (Waqas et al., 2014). In addition, there are other reports showing that a LMW compounds such as PHE were the most abundant compounds in tissues of the some mangroves, ryegrass (Lolium multiflorum Lam.) and Arabidopsis thaliana with high uptake and accumulation (Gao and Zhu, 2004; Lu et al., 2005; Alkio et al., 2005; Kang et al., 2010). The high concentration of PHE is presumably because of its mobility through the transpiration stream from roots to shoots. In another report, the soil-to-plant transfer was considered as one of the major pathways of PAHs transport into vegetable, and LMW PAHs are more susceptible to uptake and translocate than the HMW PAHs (Khan et al., 2008; Waqas et al., 2014). Furthermore, it was shown a three-ring PAH e.g. anthracene can bind to several cell-wall components such as cellulose, hemicellulose, pectin, and lignin (Wild et al., 2005), which may the reason for absorption and transduction of PAHs such as PHE in roots and shoots of $P$. australis in our study, as well. Rice also uptake PAHs with LMW from soil (Wang et al., 2015). Also, the identities of PAHs with LMW in shoots of oil-treated $R$. mucronata were similar to our study. It has been reported that shoots mostly possess two to three rings PAHs with the maximum amount (50\%) for PHE (Naidoo and Naidoo, 2018).

It seems that the detected PAHs in roots mostly uptake from soil particles adjoined to the root surfaces, then translocate from the root to the shoot either by the transpiration stream flux or by a carrier system which is reported for PHE absorption by wheat (Triticum aestivum L.) (Zhan et al., 2010). In present work, the highest accumulation rate for PAHs was found in the case of ACY in P. australis tissues collected from the monitoring sites (Figure 4). The calculated BCF for ACY reached the highest value of 1.1 for plot no.1. However, it is the fact that the values of BCFs for this compound in the samples from other locations were lower than 1. Also, in other cases, the calculated BCFs for $\sum_{16} \mathrm{PAH}$ compounds were lower than 1 , as well. It can also be said that in general, the calculated BCFs for LMW and MMW PAHs were higher than in the case of HMW PAHs. There are some outcomes in accordance with the present work showing the higher values of BCF for LMW PAHs when it compares with HMWs (Gworek et al., 2014; Li et al., 2014; Li and Ma, 2016). Gworek et al. (2014) has illustrated that three-ring PAHs have several times higher BCF than four-ring ones; moreover, the BCF values 
of four-ring were several times higher than five-ring PAHs; finally, the BCF values of six-ring PAHs were the lowest one. Based on the data shown in Figure 4, only ACY showed BCF higher than 1 in plot no. 1. Also, the mean BCF of this compound was the highest among other PAHs and it was 0.9. The BCF values lower than 1 may support the presence of mechanisms for PAH accumulation mostly from soil/root pathway. DBA was the only HMW PAHs which recorded higher BCF in plot no. 5. It appears that PAHs behavior is unpredictable in chemically contaminated area, however, high BCF value of DBA can be explained by its less content in soil where means high values of BCF. The high PAH contents probably reduced their sorption and thereby improved their availability. However, it worth mentioning that the BCF values of DBA was still less than 1 in plot no. 5.

It should be noted that the LMW and MMW PAHs containing 2-4 rings tend to take up more than the HMW PAHs which mostly are retained in soils or roots. LMW and volatile PAHs are potentially uptake from the atmosphere through the leaves, as well as by roots (Fismes et al., 2002; Li and Ma, 2016). It appears that the level and origin of contamination and type of plant species are main factors in comparison of BCF values in plants grown in different soils ( $\mathrm{Li}$ and $\mathrm{Ma}, 2016$ ), however, in the case of HMWs root uptake occurs regardless of these factors. For three-ring PAHs, the uptake pathway can be differed based on plant type, namely for monocotyledones through root but for dicotyledones, through either roots or leaves (Gworek et al., 2014). Li and Ma (2016) suggested that differences in BCFs are probably due in part to the difference in soil total organic carbon, resulting in different bioavailability of PAHs. In addition, a positive linear relationship between log RCF and log Kow was reported for the uptake of PAHs by tea plants cultivated in a hydroponic solution (Lin et al., 2006). The TF values were in PHE > FLT=ACY=CHR order. In general, transfer of PAHs from root to shoot is driven by the transpiration stream flux which is associated with the solubility of the individual PAH rather than the KOW. It seems that better water solubility of PAHs with 2 and 3 rings in the molecular structure enhances their bioavailability to roots. HMW PAHs, characterized by weak water solubility, high values of Henry's Law constants and Kow, are strongly adsorbed onto the roots preventing them from being drawn into the xylem. They stay trapped at the epidermis surface of root tissues (Kang et al. 2010). We should also add that the territory of the Atamanskoye Lake has no atmospheric emissions with PAHs and mostly characterized by chemical contamination, hence, there is no big difference between $\mathrm{TF}$ values for HMW and LMW PAHs.

\section{Conclusion}

The results of the present study carried out on monitoring soils and plants in the city of KamenskShakhtinskyi (Southern Russia, Rostov Region) demonstrated that the total PAHs level in the area of Atamanskoye Lake was very high up to $7177.9 \mu \mathrm{g} \mathrm{kg-1}$ in soil of monitoring plot no. 4 and increased the control soil level up to 14.4 times. The $\sum_{16} \mathrm{PAHs}$ concentrations for P. australis plants reached the maximum for plot no. 3 and mounted to about 3.0 and 4.1 times the PAHs level in control plant roots and above-ground parts, respectively. The most dominant PAH in the monitoring soils were PHE, BbF and DBA. In roots and above-ground parts of $P$. australis, the mean percentages of PHE reached to the highest amount followed by CHR and PYR. The BCF values of LMW PAHs with 2- and 3-rings were about 3 times higher than those of 4-6 ring PAHs. In general, the BCF and TF of total PAHs in plants were lower than 1 . Altogether, the results indicated that the PAHs in contaminated soils were taken up and accumulated in plant tissues and the distribution of these pollutants in the samples indicates a possible health risk to humans and other organisms, therefore, this problem needs further attention.

\section{Acknowledgments}

The research was financially supported by the Russian Science Foundation, project no. 19-74-10046.

\section{References}

Aina, R., Palin, L., Citterio, S., 2006. Molecular evidence for benzo[a]pyrene and naphthalene genotoxicity in Trifolium repens L. Chemosphere 65(4): 666-673.

Alkio, M., Tabuchi, T.M., Wang, X., Colon-Carmona, A., 2005. Stress responses to polycyclic aromatic hydrocarbons in Arabidopsis include growth inhibition and hypersensitive response-like symptoms. Journal of Experimental Botany 56(421): 2983-2994.

Alwan, S.W., 2016. Efficiency of the Phragmites australis and Typha domingensis roots in remediation of polycyclic aromatic hydrocarbons (PAHs) from freshwater sediments. The Iraqi Journal of Agricultural Sciences 47(2): 656666.

Alves, W.S., Manoel, E.A., Santos, N.S., Nunes, R.O., Domiciano, G.C., Soares, M.R., 2017. Detection of polycyclic aromatic hydrocarbons (PAHs) in Medicago sativa L. by fluorescence microscopy. Micron 95: 23-30. 
Bech, J., Abreu, M.M., Chon, H.T., Roca, N., 2014. Remediation of potentially toxic elements in contaminated soils. In: PHEs, Environment and Human Health. Potentially harmful elements in the environment and the impact on human health. Bini, C., Bech, J. (Eds). Springer, Dordrecht. pp. 253-308.

Bonanno, G., 2011. Trace element accumulation and distribution in the organs of Phragmites australis (common reed) and biomonitoring applications. Ecotoxicology and Environmental Safety 74(4): 1057-1064.

Bonanno, G., 2013. Comparative performance of trace element bioaccumulation and biomonitoring in the plant species Typha domingensis, Phragmites australis and Arundo donax. Ecotoxicology and Environmental Safety 97: 124-130.

Burken, J.G., Schnoor, J.L., 1998. Predictive relationships for uptake of organic contaminants by hybrid poplar trees. Environmental Science \& Technology 32(21): 3379-3385.

Chang, M.L., Wang, M.J., Kuo, D.T.F., Shih, Y.H., 2013. Sorption of selected aromatic compounds by vegetables. Ecological Engineering 61: 74-81.

Chen, Z.X., Ni, H.G., Jing, X., Chang, W.J., Sun, J.L., Zeng, H., 2015. Plant uptake, translocation, and return of polycyclic aromatic hydrocarbons via fine root branch orders in a subtropical forest ecosystem. Chemosphere 131: 192-200.

Cui, Y., Zhang, W., Sun, H., Wu, W.M., Zoul, X., 2015. Polycyclic aromatic hydrocarbon accumulation in Phragmites australis grown on constructed wetland for sludge stabilization. Journal of Residuals Science \& Technology 12(4): 215-220.

Čvančarová, M., Křesinová, Z., Cajthaml, T., 2013. Influence of the bioaccessible fraction of polycyclic aromatic hydrocarbons on the ecotoxicity of historically contaminated soils. Journal of Hazardous Materials 254: 116-124.

Davies, L.C., Carias, C.C., Novais, J.M., Martins-Dias, S., 2005. Phytoremediation of textile effluents containing azo dye by using Phragmites australis in a vertical flow intermittent feeding constructed wetland. Ecological Engineering 25(5): 594-605.

De Nicola, F., Maisto, G., Prati, M. V., Alfani, A., 2008. Leaf accumulation of trace elements and polycyclic aromatic hydrocarbons (PAHs) in Quercus ilex L. Environmental Pollution 153(2): 376-383.

Dettenmaier, E.M., Doucette, W.J., Bugbee, B., 2009. Chemical hydrophobicity and uptake by plant roots. Environmental Science \& Technology 43(2): 324-329.

Di Gregorio, S., Gentini, A., Siracusa, G., Becarelli, S., Azaizeh, H., Lorenzi, R., 2014. Phytomediated biostimulation of the autochthonous bacterial community for the acceleration of the depletion of polycyclic aromatic hydrocarbons in contaminated sediments. BioMed Research International Article ID 891630.

Dupuy, J., Leglize, P., Vincent, Q., Zelko, I., Mustin, C., Ouvrard, S., Sterckeman, T., 2016. Effect and localization of phenanthrene in maize roots. Chemosphere 149: 130-136.

Fismes, J., Perrin-Ganier, C., Empereur-Bissonnet, P., Morel, J.L., 2002. Soil-to-root transfer and translocation of polycyclic aromatic hydrocarbons by vegetables grown on industrial contaminated soils. Journal of Environmental Quality 31(5): 1649-1656.

Gałuszka, A., 2007. Distribution patterns of PAHs and trace elements in mosses Hylocomium splendens (Hedw.) BSG and Pleurozium schreberi (Brid.) Mitt. from different forest communities: a case study, south-central Poland. Chemosphere 67(7): 1415-1422.

Gao, Y., Zhu, L., 2004. Plant uptake, accumulation and translocation of phenanthrene and pyrene in soils. Chemosphere 55(9): 1169-1178.

Gworek, B., Klimczak, K., Kijeńska, M., 2014. The relation between polyaromatic hydrocarbon concentration in sewage sludge and its uptake by plants: Phragmites communis, Polygonum persicaria and Bidens tripartita. PloS One 9(10): e109548.

Gworek, B., Klimczak, K., Kijeńska, M., \& Gozdowski, D., 2016. Comparison of PAHs uptake by selected Monocotyledones and Dicotyledones from municipal and industrial sewage sludge. Environmental Science and Pollution Research 23(19): 19461-19470.

Haritash, A.K., Kaushik, C.P., 2009. Biodegradation aspects of polycyclic aromatic hydrocarbons (PAHs): a review. Journal of Hazardous Materials 169(1-3): 1-15.

ISO 10381-1, 2002. Soil quality. Sampling. Part 1. Guidance on the design of sampling programs. Available at [access date: 19.09.2019]: https://www.iso.org/standard/32423.html

ISO 10390, 2005. Soil quality - Determination of pH. Available at [access date: 19.09.2019]: https://www.iso.org/standard/40879.html

ISO 13877-2005, 2005. Soil quality - Determination of polynuclear aromatic hydrocarbons - Method Using Highperformance Liquid Chromatography. Available at [access date: 19.09.2019]: https://www.iso.org/standard/23116.html

ISO 10693, 1995. Soil quality - Determination of carbonate content - Volumetric method. Available at [access date: 19.09.2019]: https://www.iso.org/standard/18781.html

ISO 14235, 1998. Soil quality - Determination of organic carbon by sulfochromic oxidation. Available at [access date: 19.09.2019]: https://www.iso.org/standard/23140.html

ISO Guide 34, 2009. General requirements for the competence of reference material producers. Available at [access date: 19.09.2019]: https://www.iso.org/standard/50174.html

ISO NF EN 23470, 2011. Soil quality - Determination of effective cation exchange capacity (CEC) and exchangeable cations. Available at [access date: 19.09.2019]: https://www.iso.org/obp/ui/\#iso:std:68765:en

IUSS, 2015. World reference base for soil resources 2014 International soil classification system for naming soils and creating legends for soil maps. Update 2015. World Soil Resources Reports No. 106. Food and Agriculture 
Organization of the United Nations (FAO), Rome, Italy. 192p. Available at [access date: 19.09.2019]: http://www.fao.org/3/i3794en/I3794en.pdf

Jiao, H., Wang, Q., Zhao, N., Jin, B., Zhuang, X., Bai, Z., 2017. Distributions and sources of polycyclic aromatic hydrocarbons (PAHs) in soils around a chemical plant in Shanxi, China. International Journal of Environmental Research and Public Health 14(10): 1198.

Jiang, X., Wang, C., 2008. Zinc distribution and zinc-binding forms in Phragmites australis under zinc pollution. Journal of Plant Physiology 165(7): 697-704.

Kang, F., Chen, D., Gao, Y., Zhang, Y., 2010. Distribution of polycyclic aromatic hydrocarbons in subcellular root tissues of ryegrass (Lolium multiflorum Lam.). BMC Plant Biology 10(1): 210.

Keith, L.H., Telliard, W.A., 1979. ES\&T Special Report: Priority pollutants: I-a perspective view. Environmental Science \& Technology 13: 416-423.

Khan, S., Aijun, L., Zhang, S., Hu, Q., Zhu, Y.G., 2008. Accumulation of polycyclic aromatic hydrocarbons and heavy metals in lettuce grown in the soils contaminated with long-term wastewater irrigation. Journal of Hazardous Materials 152(2): 506-515.

Klánová, J., Čupr, P., Baráková, D., Šeda, Z., Anděl, P., \& Holoubek, I., 2009. Can pine needles indicate trends in the air pollution levels at remote sites? Environmental Pollution 157(12): 3248-3254.

Krzebietke, S.J., Wierzbowska, J., Żarczyński, P.J., Sienkiewicz, S., Bosiacki, M., Markuszewski, B., Mackiewicz-Walec, E. 2018. Content of PAHs in soil of a hazel orchard depending on the method of weed control. Environmental Monitoring and Assessment 190(7): 422.

Li, F., Zeng, X., Yang, J., Zhou, K., Zan, Q., Lei, A., Tam, N.F., 2014. Contamination of polycyclic aromatic hydrocarbons (PAHs) in surface sediments and plants of mangrove swamps in Shenzhen, China. Marine Pollution Bulletin 85(2): 590-596.

Li, H., Ma, Y., 2016. Field study on the uptake, accumulation, translocation and risk assessment of PAHs in a soil-wheat system with amendments of sewage sludge. Science of the Total Environment 560: 55-61.

Li, Q., Chen, B., 2014. Organic pollutant clustered in the plant cuticular membranes: visualizing the distribution of phenanthrene in leaf cuticle using two-photon confocal scanning laser microscopy. Environmental Science \& Technology 48(9): 4774-4781.

Lin, D., Zhu, L., He, W., Tu, Y., 2006. Tea plant uptake and translocation of polycyclic aromatic hydrocarbons from water and around air. Journal of Agricultural and Food Chemistry 54(10): 3658-3662.

Minkina, T., Fedorenko, G., Nevidomskaya, D., Fedorenko, A., Chaplygin, V., Mandzhieva, S., 2018. Morphological and anatomical changes of Phragmites australis Cav. due to the uptake and accumulation of heavy metals from polluted soils. Science of the Total Environment 636: 392-401.

Minkina, T., Sushkova, S., Konstantinova, E., Kumar Yadav, B., Mandzhieva, S., Konstantinov, A., Antonenko, E., 2019. Polycyclic aromatic hydrocarbons in urban soils within the different land use: A case study of Tyumen, Russia. Polycyclic Aromatic Compounds 1-15.

Naidoo, G., Naidoo, K., 2018. Uptake and accumulation of polycyclic aromatic hydrocarbons in the mangroves Avicennia marina and Rhizophora mucronata. Environmental Science and Pollution Research 25(29): 28875-28883.

Privalenko, V.V., Mazurenko, V.T., Panaskov, V.I., Moshkin, V.M., Mukhin, N.V., Senin, B.K., 2000. Ecological problems of the city of Kamensk-Shakhtinskii. Tsvetnaya pechat', Rostov-on-Don [in Russian].

Procedure of measurements benzo[a]pyrene content in soils, sediments and sludges by highly effective liquid chromatography method, 2008. Certificate 27-08: Moscow. 27p. [in Russian].

Ryan, J.A., Bell, R.M., Davidson, J.M., O'connor, G.A., 1988. Plant uptake of non-ionic organic chemicals from soils. Chemosphere 17(12): 2299-2323.

Serafimovski, T., Tasev, G., Stefanova, V., 2014. Anthropoghenic soil contamination connected with active mines, smelting and plants in the Republic of Macedonia. Eurasian Journal of Soil Science 3(4): 293 - 302.

Shein, E.V., 2009. The particle-size distribution in soils: problems of the methods of study, interpretation of the results, and classification. Eurasian Soil Science 42(3): 284-291.

Simonich, S.L., Hites, R.A., 1995. Organic pollutant accumulation in vegetation. Environmental Science \& Technology 29(12): 2905-2914.

Sun, F., Wen, D., Kuang, Y., Li, J., Li, J., Zuo, W., 2010. Concentrations of heavy metals and polycyclic aromatic hydrocarbons in needles of Masson pine (Pinus massoniana L.) growing nearby different industrial sources. Journal of Environmental Sciences 22(7): 1006-1013.

Sushkova, S., Minkina, T., Mandzhieva, S., Borisenko, N., Vasilyeva, G., Kizilkaya, R., Askin, T., 2015. Approbation of express-method for benzo[a]pyrene extraction from soils in the technogenic emission zone territories. Eurasian Journal of Soil Science 4(1): 15-21.

Sushkova, S.N., Minkina, T.M., Mandzhieva, S.S., Vasilyeva, G.K., Borisenko, N.I., Turina, I.G., Kızılkaya, R., 2016. New alternative method of benzo [a] pyrene extractionfrom soils and its approbation in soil under technogenic pressure. Journal of Soils and Sediments 16(4): 1323-1329.

Sushkova, S.N., Minkina, T.M., Mandzhieva, S.S., Deryabkina, I.G., Vasil'eva, G.K., Kızllkaya, R., 2017. Dynamics of benzo[ $\alpha]$ pyrene accumulation in soils under the influence of aerotechnogenic emissions. Eurasian Soil Science 50(1): 95-105.

Suzuki, N., Koussevitzky, S.H.A.I., Mittler, R.O.N., Miller, G.A.D., 2012. ROS and redox signalling in the response of plants to abiotic stress. Plant, Cell \& Environment 35(2): 259-270. 
Toyama, T., Furukawa, T., Maeda, N., Inoue, D., Sei, K., Mori, K., Ike, M., 2011. Accelerated biodegradation of pyrene and benzo[a]pyrene in the Phragmites australis rhizosphere by bacteria-root exudate interactions. Water Research 45(4): 1629-1638.

Waqas, M., Khan, S., Chao, C., Shamshad, I., Qamar, Z., Khan, K., 2014. Quantification of PAHs and health risk via ingestion of vegetable in Khyber Pakhtunkhwa Province, Pakistan. Science of the Total Environment 497: 448-458.

Wang, Y., Wang, S., Luo, C., Xu, Y., Pan, S., Li, J., Ming, L., Zhang, G., Li, X., 2015. Influence of rice growth on the fate of polycyclic aromatic hydrocarbons in a subtropical paddy field: a life cycle study. Chemosphere 119: 1233-1239.

Wang, Z., Liu, Z., Yang, Y., Li, T., Liu, M., 2012. Distribution of PAHs in tissues of wetland plants and the surrounding sediments in the Chongming wetland, Shanghai, China. Chemosphere 89(3): 221-227.

Wild, E., Dent, J., Thomas, G.O., Jones, K.C., 2005. Direct observation of organic contaminant uptake, storage, and metabolism within plant roots. Environmental Science \& Technology 39(10): 3695-3702.

Yaroshchuk, A.V., Maksimenko, E.V., Borisenko, N.I., 2003. Development of a technique for extracting benzo[a]pyrene from soils. Izvestiya vuzov. Severo - Kavkazskii region. Natural Sciences. Prilozhenie 9: 44-46. [in Russian]

Zhan, X.H., Ma, H.L., Zhou, L.X., Liang, J.R., Jiang, T.H., Xu, G.H., 2010. Accumulation of phenanthrene by roots of intact wheat (Triticum acstivnm L.) seedlings: passive or active uptake? BMC Plant Biology 10(1): 52.

Zhan, X., Zhu, M., Shen, Y., Yue, L., Li, J., Gardea-Torresdey, J. L., Xu, G., 2018. Apoplastic and symplastic uptake of phenanthrene in wheat roots. Environmental Pollution 233: 331-339.

Zhang, C., Yao, F.E.N.G., Liu, Y.W., Chang, H.Q., LI, Z.J., Xue, J.M., 2017a. Uptake and translocation of organic pollutants in plants: A review. Journal of Integrative Agriculture 16(8): 1659-1668.

Zhang, S., Yao, H., Lu, Y., Yu, X., Wang, J., Sun, S., Liu, M., Li, D., Li, Y.F., Zhang, D., 2017b. Uptake and translocation of polycyclic aromatic hydrocarbons (PAHs) and heavy metals by maize from soil irrigated with wastewater. Scientific Reports 7(1): Article number: 12165.

Zhang, Z., Rengel, Z., Meney, K., 2010. Polynuclear aromatic hydrocarbons (PAHs) differentially influence growth of various emergent wetland species. Journal of Hazardous Materials 182(1-3): 689-695.

Zohair, A., Salim, A.B., Soyibo, A.A., Beck, A.J., 2006. Residues of polycyclic aromatic hydrocarbons (PAHs), polychlorinated biphenyls (PCBs) and organochlorine pesticides in organically-farmed vegetables. Chemosphere 63(4): 541-553.

Zuo, Q., Lin, H., Zhang, X.L., Li, Q.L., Liu, S.Z., Tao, S., 2006. A two-compartment exposure device for foliar uptake study. Environmental Pollution 143(1): 126-128. 